International Journal of Modern Physics A, Vol. 11, No. 12 (1996) 2231

(C) World Scientific Publishing Company

\title{
ERRATA
}

\section{ON THE EQUIVALENCE OF DUAL THEORIES}

\author{
[INT. J. MOD. PHYS. A, Vol. 11, No. 7 (1996) 1315-1328] \\ A. SUBBOTIN and I. V. TYUTIN
}

In Sec. 4.1, the correct formula should read:

The calculation gives

$$
\begin{aligned}
& \hat{R}_{(i j)}=-\frac{3+B^{4}}{4 \pi\left(1+B^{2}\right)^{3}} \delta_{i j}+\frac{3+8 B^{2}+B^{4}}{4 \pi\left(1+B^{2}\right)^{3}} B^{i} B^{j}, \\
& \hat{R}_{[i j]}=-\frac{1}{\pi} \frac{1}{\left(1+B^{2}\right)^{3}} \epsilon^{i j k} B^{k} .
\end{aligned}
$$

